\title{
MANERAS DE VERSE, DE ESTAR Y DE SOCIALIZAR EN LA BOGOTÁ DE 1920 A 1960, A TRAVÉS DEL VESTIDO
}

Luz Mariela Gómez ${ }^{1}$

Profesora de la Universidad de los Andes

luzgomez@uniandes.edu.co.

María Clara Salive ${ }^{2}$

Candidata a doctora en Estética y Crítica,Arte y Arquitectura

Universidad Nacional de Colombia

mc.salive169@uniandes.edu.co

\section{Resumen:}

El vestido, como manifestación cultural, nos permite acercarnos a imaginarios de clase, ocupación, edad o género presentes en un grupo de individuos en determinadas épocas y lugares. Así, la recepción de la moda y sus usos en diversos rituales de encuentro y socialización, pueden ser leídos como hijos de su momento histórico; reflejos de los cambios de pensamiento y los conflictos que estos suponen. Significados que se entretejen y quedan plasmados tanto en las imágenes (iconografía) como en los objetos que se conservan y que en la primera mitad del siglo XX en Colombia y de manera particular en Bogotá, dan cuenta del disímil significado de ser modernos y habitar en la ciudad.

Por lo anterior, este artículo muestra algunos de los significados que adquiere el vestido en Bogotá de 1920 a 1960; a partir de documentos bibliográficos y revistas de la época; en especial, la Cromos. Todo esto, para dar cuenta de las posibilidades expresivas del vestido y las imágenes que nos quedan de su uso. Imaginarios alrededor de la vida urbana, el cuerpo, la higiene, el habla culta y la urbanidad, que hacen parte del mito de la Atenas Suramericana, antes que la vulgarización y la democratización de algunas formas alrededor de 1940, cambiaran la idea del cachaco y la dama santafereña. Un ideario que nos permite entender la relación entre diseño e historia cultural, en medio de las transformaciones que el protagonismo de la clase media, después de los años 40, trae consigo tanto en el vestido como en las ideas que circulan a la par que la ciudad crece a pasos agigantados.

Palabras Clave: Bogotá, vestido, moda, historia material.

\begin{abstract}
:
the dress, as a cultural manifestation, allows us to know the class, occupation, age and genre imaginaries presents in a group of individuals in certain epochs and places. The reception of fashion and its uses in various rituals of meeting and socialization can be taken as products of their historical movements; reflects of thought changes and conflicts. Meanings interweaved as in the images as in the objects conserved and that in the first half of Twentieth Century in Colombia and in a special way in Bogotá, shows the complex meaning of being modern and inhabit the city.

This article shows some of the meanings of the dress in Bogotá between 1920 - 1960, parting of bibliographical documents and magazines, specially, Cromos. All to show the imaginaries of the urban life, the body, the health, the cult speaking and the urbanity, that constitutes the myth of the Suramerican Athens, before the vulgarization and democratization of some ways, in 1940, change the idea of Cachaco and the Santafereña Lady.
\end{abstract}

Keywords: Bogotá, dress, fashion, material history 
Ese ser que habita el cuerpo también habita un lugar y entre ese cuerpo y ese lugar está el vestido. Así, vestirse es ante todo recubrir la piel; convertir ese cuerpo desnudo y privado del que se goza en el espacio íntimo, en uno público, discursivo y expuesto ante la mirada de los otros. Sobre todo eso: discursivo.Y es tras ese discurso que el vestido se puede leer como parte de las huellas que cada grupo devela de lo que piensa de sí mismo y de los otros. Miradas de género, concepciones sobre el cuerpo, presupuestos sobre la edad y la clase social quedan expuestos mediante la lectura de cada prenda decodificada en su uso y su forma. Por ello este estudio parte de estas huellas para interrogarse:¿De qué forma estudiar el vestido, cómo signo de las diversas concepciones propias de un proyecto civilizador que se escenifica en las costumbres y en las representaciones de ser modernos y habitar en la ciudad, puede aportarle a la historia cultural de Bogotá entre 1920 y 1960 ?

Interrogante que por la amplitud del período de tiempo que abarca el estudio, por ahora, presenta una serie de ejemplos de los resultados que se van derivando de la metodología aplicada. Como lo mostraremos a continuación, esta implica acercarse a los documentos iconográficos y contextualizarlos mediante la perspectiva de análisis que se deriva de comparar lo que pasaba en el exterior, con los significados que adquiere el vestido en Bogotá (Figura 1), gracias a los procesos de negociación de sentido que cada cultura le otorga a las prendas con que se comunica.

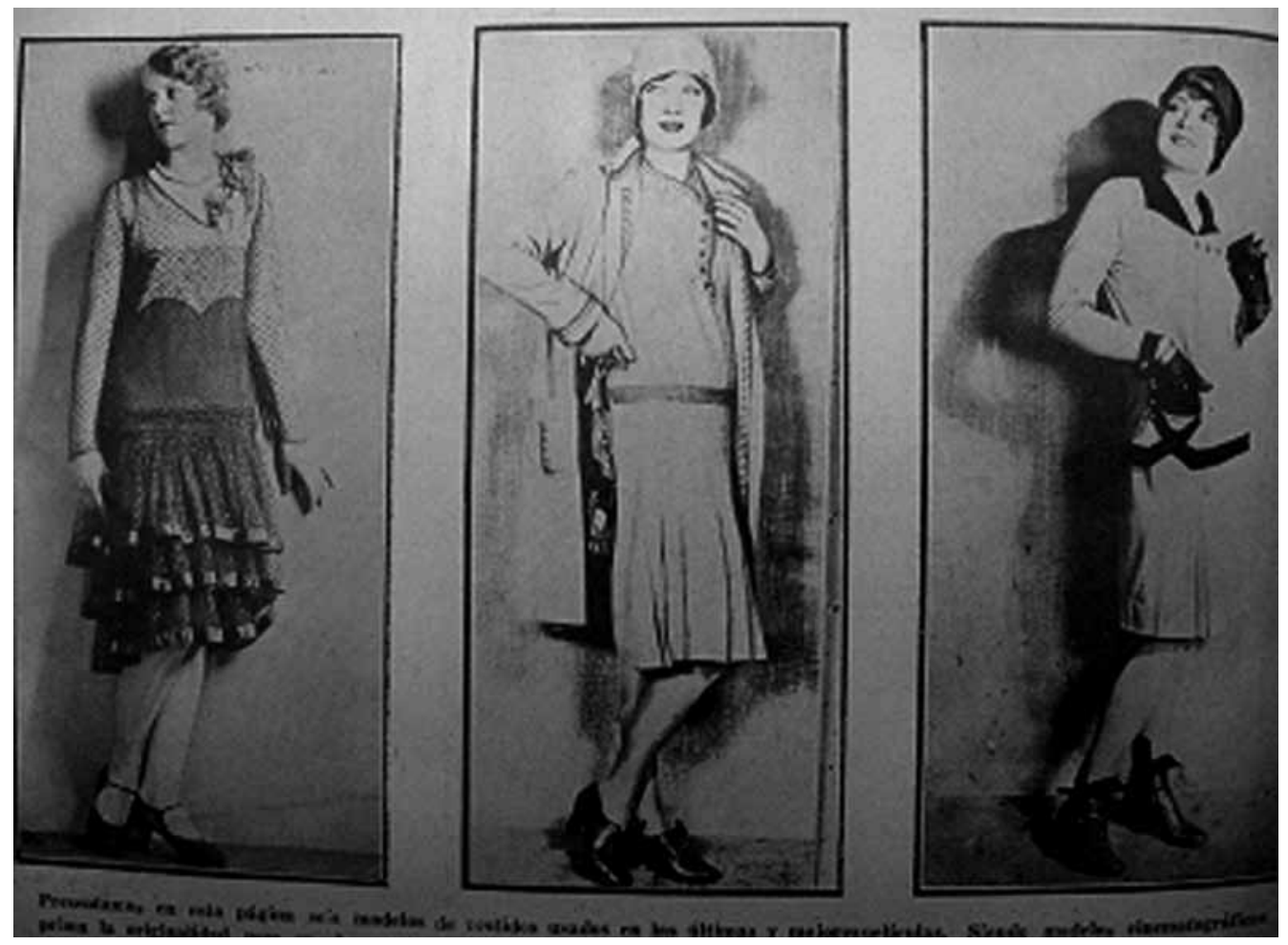

Figura 1: Las tres actrices de cine que aparecen retratadas en la imagen lucen los modelos que influyen en la escogencia de los atuendos en Bogotá durante los años veinte: período de entre guerras, en el que la sobriedad con que patrióticamente se vistieron las europeas, aquí fue un símbolo de estatus de una elite que, durante este periodo, es la única con el poder adquisitivo que supuso estar a la moda. Revista Cromos, 1929. 
Comencemos entonces por dibujar el escenario; dar una idea de las coyunturas con que se reciben los años 20 en Colombia y cómo ciertas transformaciones y constantes en dicho entorno nos llevan a situarnos decenio tras decenio en cambios contradictorios y disímiles entre las creencias y la ropa que se porta. Lo anterior bajo el presupuesto de que cada objeto que se estudia implica reconstruir el contexto en que aparece y los procesos tecnológicos, sociales y económicos que influyen en su producción y uso. En cuanto el consumo sólo puede entenderse desde los significados y las ideas que comparte una colectividad.

Para comenzar, entre 1920-1930 debemos remontarnos a una ciudad que se debate en medio de las contradicciones propias de la época: por un lado la sombra de la pobreza, la inestabilidad política y los ecos de la Guerra de los 1000 días se cuelan por todas partes y, por el otro, unos pocos disfrutan de los privilegios que la desigualdad social le provee a las élites. De 1920 a 1930 puede hablarse de una situación económica relativamente promisoria: mientras en el mundo, tras el final de la Primera Guerra Mundial se instituye la Sociedad de Naciones con miras a evitar que el conflicto volviera a repetirse y se comienza a reactivar la economía, sobre todo en Estados Unidos, Colombia se ve favorecida con esto y la exportación de café da impulso a la creación de pequeñas empresas que producen y venden a nivel local, gaseosas, cervezas, jabón, tabaco, textiles, fósforos, entre otros. Esta bonanza, como se puede seguir en la revista Cromos, se hace mayor en el último lustro de los años 20 con los 25 millones de dólares de la indemnización por Panamá, hecho al que se le suma la reorganización del sistema bancario (Uribe Celis, 1984 ).

En 1930 esta corta danza de los millones se ve truncada por la Gran Depresión que sufre los Estados Unidos en 1929, mientras en Alemania sube Adolf Hitler al poder (1933) y en medio de los grandes totalitarismos se prepara el panorama que desemboca en la Segunda Guerra Mundial. Colombia, por su parte, saluda con optimismo al presidente Olaya Herrera con quien se inicia la hegemonía liberal, la cual recibe del anterior decenio conservador un déficit fiscal y una acrecentada deuda externa, fruto de los malos manejos que se le dieron a los dineros atrás mencionados (Fundación Misión Colombia, 1989).

Como se puede ver, los años 20 dan cuenta de dos corrientes esenciales a la hora de enmarcar este objeto de estudio. Por un lado, en Europa la falta de hombres que genera la guerra impulsa a que la mujer abandone el hogar y con este el aparatoso miriñaque y el apretado corsé que durante la Segunda Revolución Industrial la mantuvo confinada a la casa y en la posición de quien tiene un cuerpo más para ser exhibido que para moverse o trabajar. Por el otro, el diseño de moda, entre otras estrategias para reactivar el consumo, genera una dinámica de cambio que acelera los largos periodos en que la historia del vestuario mantenía cada estilo vigente. Desde finales del siglo XIX Charles Frederick Worth (1892) transforma la concepción de la ropa encomendada a sastres o modistas, según el sexo, para dar paso a colecciones individuales que se ponían a disposición de las clientas para su 
reproducción. Continuando con esa línea, Paul Poiret (18791944) y, más adelante, Coco Chanel (1883-1971), instauran un discurso de la moda más cercano al que circula actualmente. Con ello se abre el imperio de signos efímeros, un devenir de las cosas que no perduran, de los estilos que van y vienen en cada estación y una búsqueda que coincide con una mujer que se libera y descubre su corporeidad, antes apretada y sometida en formas coercitivas tales como las del corsé y separada del posible rose de los otros por enaguas almidonadas o armazones de metal. Dama que se respetara para ser considerada como tal, nunca, hasta después de Poiret, deja ver sus pantorrillas (Lehnert, 2000).

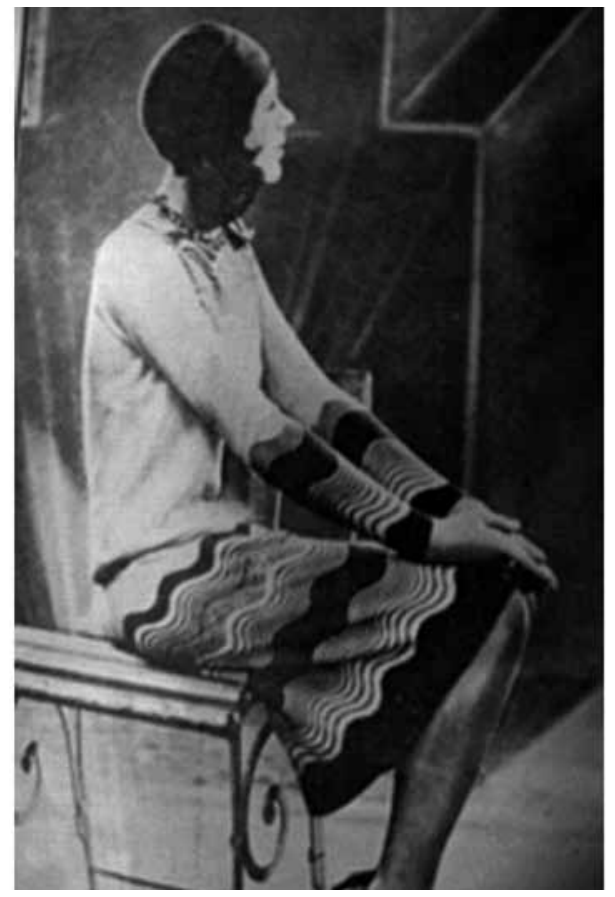

Figura 2: El largo de la falda que muestra la modelo de esta fotografía, hace parte de una de las transformaciones más debatidas dentro de la indumentaria femenina. Las bogotanas de ese entonces adoptan el cambio, en la medida que moda y distinción se sobreponen incluso a las amenazas que desde el púlpito condenan estas tendencias y a sus usuarias. Revista Cromos, 1929

No obstante, en Colombia esa mujer de élite que se viste a la moda poco aspira a salir de su hogar y si se corta el pelo al estilo bobbet o se pone un sombrero cloche, es sólo parte de esa necesidad de cambio que inserta a la mujer en las dinámicas de una modernidad que aquí poco tiene que ver con un cambio social, y más bien se traduce en la adquisición de bienes suntuarios de un grupo social reducido que quiere mantener su estatus y pugna por diferenciarse (Figura 3). Ser moderno en Bogotá fue más bien un adjetivo que indistintamente se le antepone a estar al día, adquirir lo último, admirar todo aquello que viene de fuera, tener un sabor cosmopolita y acceder a cierto capital cultural indispensable para mantenerse y legitimar el capital social. Dos conceptos que hacen de la moda en Bogotá no el fenómeno de democratización inherente a la vida urbana como la concibe Simmel en la París finisecular (Frisby, 1994), sino un orden constitutivo y aristocrático, donde la exhibición de bienes suntuarios y escasos es esencial para diferenciarse de muchos otros que por esa misma época desfilan por la calle con su ruana, pañolón o faldón colonial. 


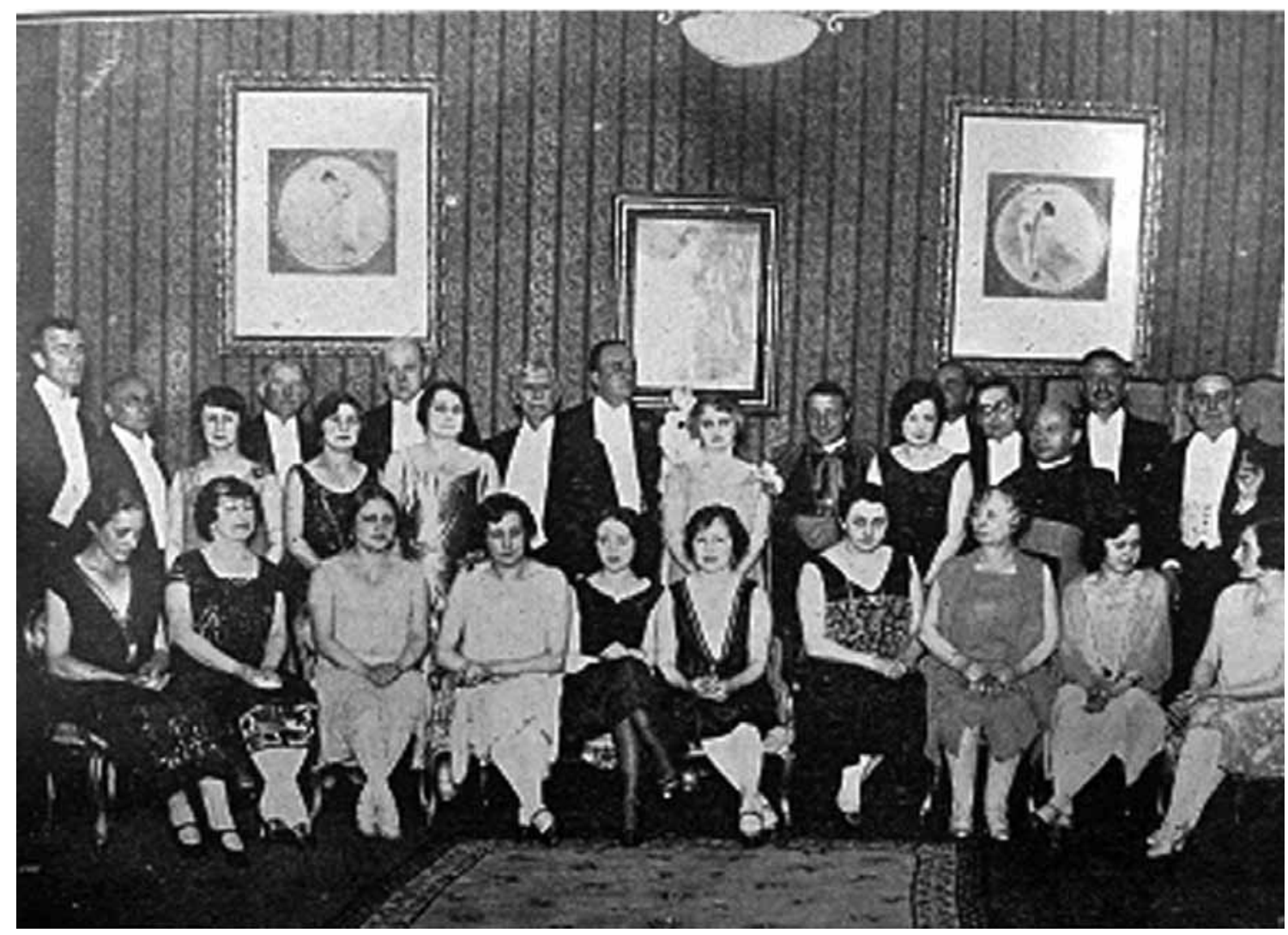

Figura3: esta fotografía tomada de las páginas sociales, da cuenta de lo rápido que se imita el estilo europeo en la indumentaria de la clase alta capitalina. El pelo corto, los vestidos de talle bajo y las pantorrillas descubiertas, son algunos de los cambios que evidencian esta drástica transformación en la moda. Revista Cromos, 1928

El habla culta, el conocimiento de varios idiomas y el vestido son aún más indispensables en una ciudad en que ricos y pobres cohabitan en una proximidad incómoda para quienes buscan legitimar su estamento en la sociedad. Desde que comienza el siglo en Bogotá se adelantan significativas transformaciones en sus estructuras administrativas y políticas, lo que da como resultado cambios en las dinámicas demográficas, las condiciones de vida y la renta del suelo. Las reformas urbanas, en principio, consisten en la subdivisión de grandes casas coloniales en varios lotes. Así, esa densificación que comienza desde finales del siglo XIX es la respuesta para solucionar la demanda de vivienda, lo que supone que clases sociales opuestas compartan la misma vecindad y en muchos casos hasta la misma casa. En palabras de Lleras Camargo:

La pobreza lo dominaba todo. Y la ciudad era una mezcla de modos de vivir conjuntamente, entre ricos y pobres. En todas las casas de los primeros, generalmente de dos pisos sobre la calle, vivían abajo, o tenían sus tiendas, los artesanos, y se oían en la calle sus alegatos, sus imprecaciones y hasta los ecos de sus juergas rudas y agresivas. La idea de vivir en barrios separados y exclusivos enclaves de clase, no existían en la ciudad, hecha a la española. Ni siquiera había preeminencia entre los distintos cuarteles de la ciudad (Lleras Camargo, 1975).

Dentro de este panorama, construir reductos para subrayar esa diferencia como lo fueron los clubes, es una estrategia casi perentoria a la hora de conservar el capital social y cultural que garantiza la permanencia o la movilidad dentro del campo. Son estos mismos clubes sociales - el Jockey Club, El Club del Country, El Polo Club, entre otros- los que a su vez dinamizan un cambio substancial en el vestido. Si bien desde el púlpito acusan de pecadores, masones y liberales a todos aquellos que se hacen de esos 
ropajes, ser modernos también es acceder a un cambio en la concepción del cuerpo. Ya no se martiriza esta perturbadora fuente de deseo sino, gracias a ciertas ideas médicas provenientes de la ilustración, se concibe que en "cuerpo sano, mente sana" y con ello se promueve el ejercicio y los cambios inherentes en la indumentaria de quien necesita moverse. A pesar de los improperios por parte de la iglesia, es más fuerte el miedo a ser condenado en esta tierra a la exclusión social, que las amenazas de condena eterna. Es así como en medio de la hegemonía conservadora y en el decenio que le sigue a gobierno liberal, las mujeres modernas se ejercitan con faldas un poco más cortas que los trajes de calle que ya para ese entonces y contra toda norma anterior, dejan en evidencia los seductores tobillos (Figura4).

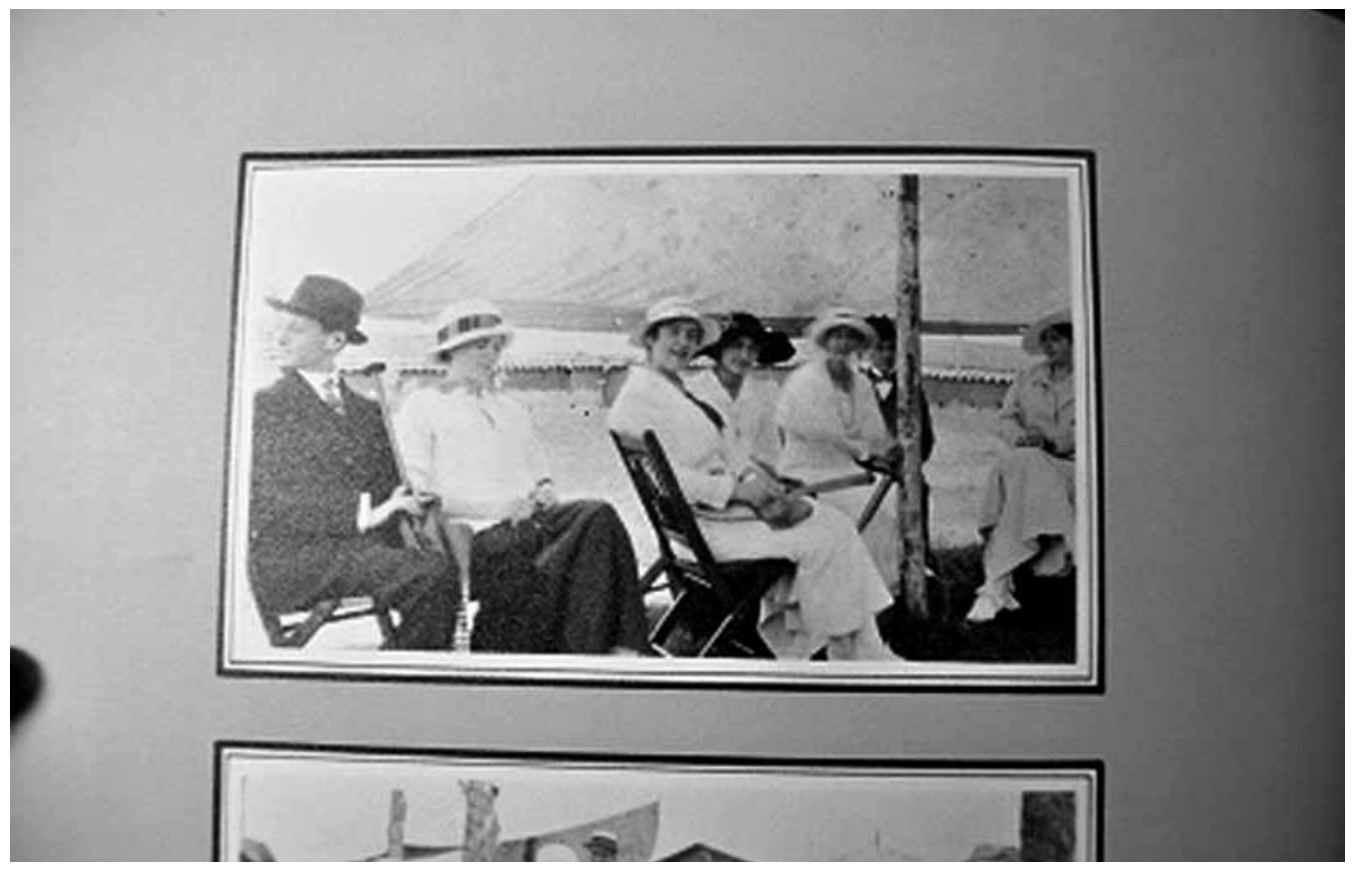

Figura 4: Esta fotografía de 1920 muestra la indumentaria deportiva que invita a las mujeres a realizar actividades físicas, entre las que desde un principio estuvo el tenis. Vestidas de blanco, con blusas al estilo marinero, concurren a dicha práctica considerada propia de las élites de ese entonces. Fotografía tomada de: Herrera Roberto y Carrizosa Umaña (1967).

No obstante, en el decenio de 1920 a 1930 son pocos los deportes que se consideran adecuados para señoritas. Es más, en un principio, el atuendo es sólo para animar a sus esposos y se aconsejan los cosméticos más que el ejercicio, para mantener esa belleza y elegancia que acompaña el discurso de ser modernos. Lo mismo puede decirse del pantalón. Así, aunque en la Cromos se exhibe una mujer con bloomers (una especie de falda pantalón) el artículo que acompaña la fotografía desvirtúa con ironía la posibilidad de que las mujeres decentes se hagan a esta prenda: "Por entonces, dijo Benavente que si el pronóstico de San Pablo estaba ya para cumplirse, que si los hombres perseguidos por las mujeres habían de refugiarse en las copas de los árboles, y que si las mujeres habían de trepar, los pantalones eran sin duda necesarios." (Miravel, Cromos, 1924, No. 407). Faltarán muchos años para que el pantalón sea bien visto en las mujeres, lo que no impide este afán de las élites por apropiarse de otras prendas de la moda parisina a la par que cuidan que sus hijos y esposos luzcan trajes importados de Londres. 
Una fotografía de domingo en una de las paradas del tren de la Sabana o la panorámica de cualquier vía en construcción, evidencian el fuerte contraste entre aquellos que se han apropiado del discurso de la vida urbana y aquellos rezagados por los vientos cambiantes de ese capitalismo que se cuela por todas partes y altera los ritmos del consumo (Castro Gómez, 2009). Ellos van de paño inglés, bombín o sombrero fedora y los otros de ruana, alpargatas y sombrero de fique, como lo hicieron sus ancestros muchos años atrás. Ellas de abrigo y sombrero acampanado (clache) y las otras con pañolón de lana y faldón negro. Ellas tienen una prenda para cada ocasión y para cada hora del día, los otros apenas alteran su vestuario para ir a misa los domingos. Así podríamos continuar con las abismales diferencias entre unos y otros.
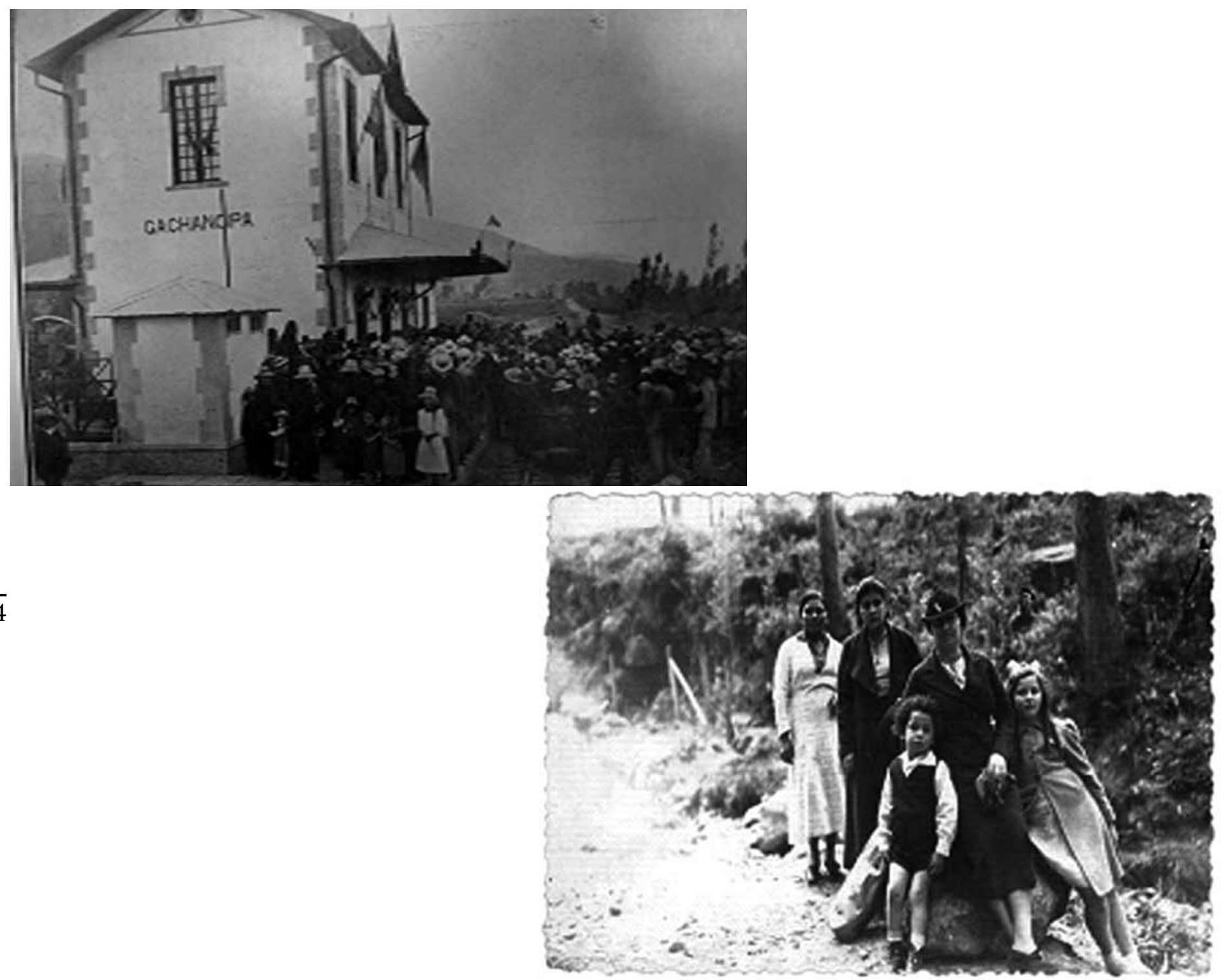

Figuras 5 y 6: Una mirada a la estación del tren (izq.), en comparación con la familia que visita el domingo el Parque Nacional, parecerían remitirnos a dos épocas diferentes. Mientras el vestido campesino aún lo utilizan inclusive los obreros que transitan en la ciudad, la otra clase social disfruta de los cambios de la moda (der.) Revista Cromos de 1929. (izq.) Álbum Familiar de Bogotá (der.). 
Sin embargo, en cuanto a vestuario y ciudad, son muchas las transformaciones, teniendo en cuenta la incursión de la arquitectura propiamente moderna en la década del 30 al 40 y todos los cambios que tras la hegemonía conservadora se experimentan en la vida social y que con la incursión del cine, la radio y el avión, se vienen preparando desde la década anterior. Este decenio bajo el proyecto urbanístico de Karl Brunner, da inicio a la construcción de lo que sería la Ciudad Universitaria y con esta obra a los primeros edificios propiamente modernos que tuvo la capital. Para sintetizar, entre 1934 y 1938 aparecen la represa de La Regadera y la planta de tratamiento de agua de Vitelma; se construye el aeropuerto de Techo y se llevan a cabo corredores viales como la Carretera de Circunvalación y el Paseo Bolívar, entre otras zonas residenciales como Santa Teresita, Teusaquillo y el barrio Palermo, los cuales se van urbanizando a la vez que se levantan, por ejemplo, la Biblioteca Nacional (1934), al estilo art- deco neoyorkino; que un poco antes ya había incursionado en el vestuario.

Paralelas a estas renovaciones urbanas en la década de 1930 a 1940 tienen lugar significativas transformaciones que dan comienzo a lo que sería la aparición de la clase media bogotana, hecho que incide en la educación y va a reflejarse en la indumentaria tanto de esta naciente clase, como de los obreros. Así, Jorge Eliecer Gaitán durante su alcaldía inicia campañas de culturalización que van desde el pie descalzo, pasan por la alpargata y desembocan en la generalización del uso de zapatos en los obreros. También, bajo corrientes higienistas, las marchantas son provistas de gorros y delantales, poco antes de que implementar el uniforme en los choferes de servicio público le costara gran parte de su popularidad como alcalde a Gaitán (Fundación Misión Colombia, 1989, 40-46). Estos cambios paulatinos en el vestuario reconfiguran después de 1930 el paisaje humano. Así, mientras las recuas de mulas, los elegantes carruajes y los pocos Fort-t se entrecruzan en las calles de 1920, después del 30 hay más automóviles, abrigos, bombines y paraguas, que las ruanas y los sombreros de fique con que se cruzan los "elegantes" en el decenio anterior.

A su vez, en 1930 se percibe una diferencia menos radical entre ricos y pobres: la venta de telas a crédito puerta a puerta por parte de los inmigrantes palestinos libaneses (los turcos) y los judíos (los polacos), se convierte en una de las estrategias para vestir bien de estas clases emergentes. Sin embargo, la lógica de la diferenciación sigue presente en los lugares de encuentro que escogen las élites y en su vestuario siempre existe un material, una marca o un tipo de confección que le permite a los dueños del capital simbólico, cultural, social y material enfatizar en su supremacía frente a lo popular.

Ya fuera importado o reproducido del original, son básicamente estos dos estilos los que atraviesan los dos primeros decenios de este estudio: en primer lugar, el orientalismo nouveau que retoma Poiret de las bailarinas rusas, y que sólo se considera apropiado para la noche y el art deco que se generaliza en el vestido tipo sastre cuya abanderada es Chanel. Este último hereda las formas precisas y el funcionalismo propio de la arquitectura; un estilo moderno que permea el internacional y que se mantendrá casi invariable hasta la actualidad. 
Ahora bien, es indispensable remitirse a qué pasa en Bogotá después del 9 de abril de 1948 y preguntarse por las dinámicas derivadas de una ciudad que crece a pasos agigantados, duplica su población y con ella una clase media que se adscribe a su grupo de referencia mediante el vestido. Así, ese crecimiento fruto de la migración por la violencia bipartidista, entre otras muchas razones derivadas de las oportunidades de estudio y de trabajo que brinda la capital, traen consigo individuos que bajo las dinámicas económicas del capitalismo, son consumidores de una oferta cada vez mayor de bienes suntuarios. Si en los años 20 son sólo unos cuantos los que gozan de esas prendas exclusivas, hechas a la medida o traídas del exterior, después del 50, aumenta la oferta y la demanda, y con ello en el paisaje urbano disminuyen los atuendos campesinos y llegan a encontrarse con el cachaco típico bogotano, personajes variados y coloridos de diferentes regiones del país y, en menor número, de otras partes del mundo. Ésta migración y toda la influencia foránea recibida a través de las revistas, la publicidad, el radio, el cine y la televisión, dan como resultado una transformación en las costumbres y en los gustos de los habitantes capitalinos.

Bogotá es una ciudad cosmopolita y tiene la peculiaridad de que acoge a quien llega: el andarín latinoamericano, que se perdió en su ruta, o el mecánico escandinavo que vino contratado por una fábrica y quien siempre oyó hablar del dorado y de las gemas escondidas en esta América nuestra o el compatriota de un rincón de nuestro mapa, que llegó al altiplano a estudiar las leyes o el arte de curar una hernia (...)Luego se han quedado.Y aquí han armado su tolda, y forman parte de este conglomerado inquieto (...).En las vías, en los parques, en los cines, en las cafeterías de Bogotá, una abigarrada multitud que habla de muchas formas y tiene las facciones de muchas razas, se confunden en caótica y colorida comunidad. Porque la música afrocubana, con los corridos y el swing y el fútbol argentino, con los luchadores europeos de triste acento centroamericano; y la revolucionaria vestimenta de la época, con sus chaquetas color zapote-loro y sus camisas daltonianas con palmeras y caimanes, eso, todo eso ha dado una nueva personalidad de juventud a la ciudad del "Águila Negra”. (Guerra, Revista Cromos, 27 de febrero de 1956, 12)

¿Bajo qué coyunturas se dan estos cambios? En el mundo occidental después de vivir el horror y las penurias de las dos guerras mundiales que diezman gran parte de la población, arrasan las ciudades europeas y resquebrajan la vida familiar establecida, antepone entre sus valores lograr el bienestar, reivindicar el ocio y restablecer lo perdido. Para lograr estas metas se establecen dos objetivos principales: alcanzar el milagro económico que representa entrar en la dinámica del consumo y restablecer el núcleo familiar. Los roles del hombre y la mujer se redefinen, él es el gobernante y quien resuelve la economía del hogar, ella es la esposa, su papel principal es apoyar a su marido dentro y fuera de la casa, criar a sus hijos moral y físicamente sanos y, para lograrlo, se convierte en una profesional del cuidado del hogar: es la responsable del buen funcionamiento de su casa y de su familia, todo debe marchar perfectamente y esto debe reflejarse tanto en la apariencia de la casa como en la de cada una de las personas a su cargo: los hijos deben verse saludables, el marido aparecer como un profesional exitoso y ella debe lucir siempre bella. En la década de los 50 las mujeres bogotanas no se escapan del postulado anteriormente mencionado y, para ponerse al día, algunas deciden escribirle a revistas como la Cromos para pedirle consejos, como puede verse en un artículo relacionado con la salud de los maridos que se publicó en el año de 1953. 
¿Qué su marido está aparentemente bien? Vea, amiga, hay cinco puntos esenciales

que deben reglamentar su conducta

Si su marido sobrepasa su peso, necesita un régimen

Vigile que su marido descanse lo suficientemente...

(el ejercicio no debe dejarlo exhausto, sino flojo en sus nervios)

Su marido debe tener una ocupación secundaria que lo estimule...

(sopórtelo con una sonrisa si todos los domingos pretende mejorar la instalación eléctrica.

Pondrá cara seria, pero se entretendrá, y eso es muy importante. En todo caso usted tiene

tiempo, los lunes, de hacer venir a un electricista de verdad para poner las cosas en orden,

Sea lo bastante diplomática como para obligarlo a ver a un médico...cada cinco años

hágale hacer un electrocardiograma (RevistaCromos, Enero 17 de 1953, 32)

Esta revista, a lo largo de sus publicaciones, también informa a sus lectoras sobre los últimos preceptos de los más destacados diseñadores en la capital de la república. Las boutiques, tiendas que simulan la forma de mostrar y vender de las casas de alta costura, creadas en su mayoría por mujeres emigrantes de Europa quienes, antes de migrar, ya han trabajado en el oficio de la confección en sus países de origen, comparten ventas con un nuevo estilo de almacén denominado por departamentos como Sears Roebuck. Este abre sus puertas en Bogotá en 1954 y brinda la opción a los capitalinos de comprar al contado o a crédito artículos novedosos y variados, tales como ropa, muebles y electrodomésticos, lo que le permite a la recién consolidada clase media, acceder a bienes que antes eran de uso exclusivo de las elites.

Figura 7: La publicidad de Sears y el Banco Popular resumen el ideal de mujer de la época: ella es la encargada de administrar los bienes de su marido, sin con ello perder la elegancia y porte que debe caracterizar a esta naciente clase media que adquiere protagonismo en el espacio urbano (Revista Cromos, 1953)

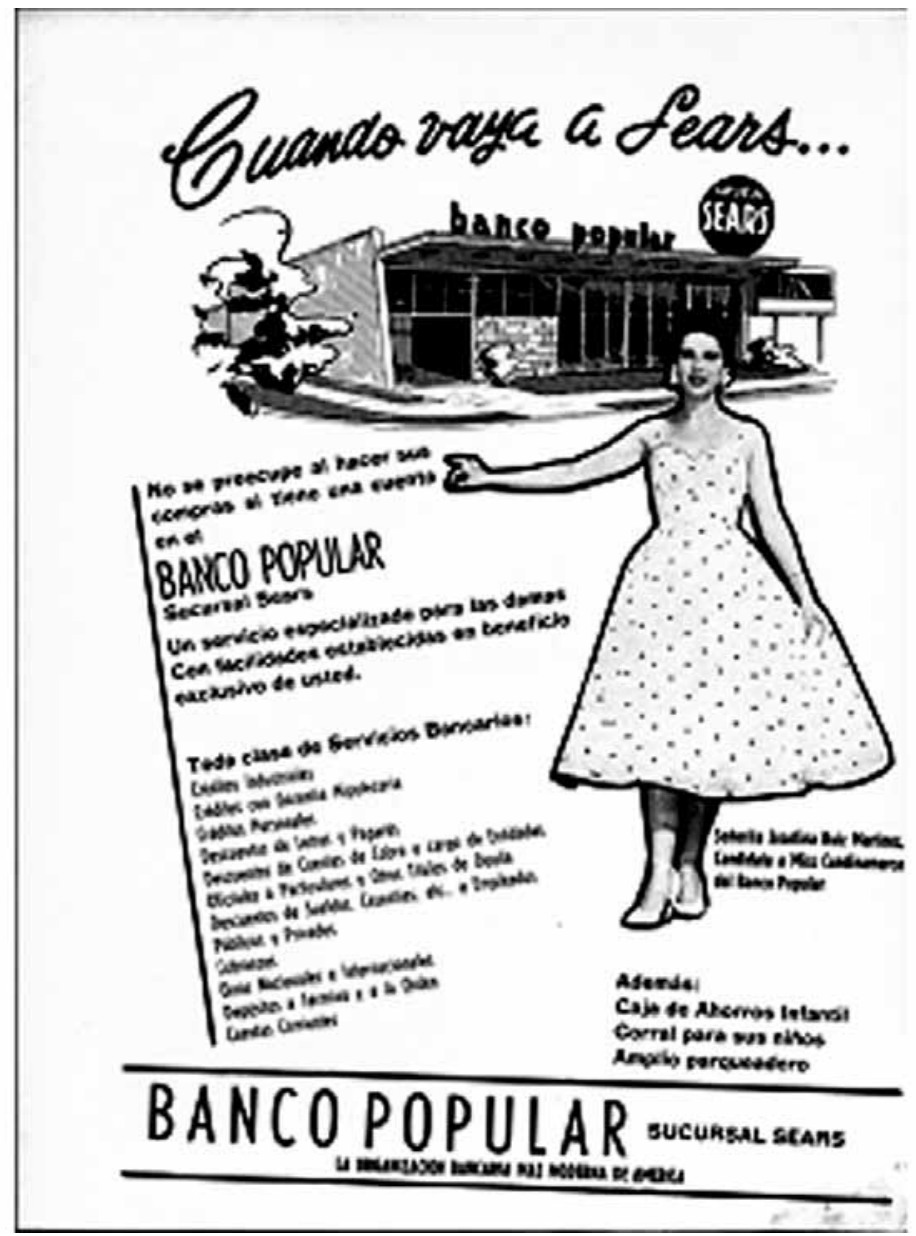


Pero ¿cuál es el ideal de perfección física en los años cincuenta? Si bien en nuestro país persiste hasta la mitad del siglo XX el ideal de la mujer caritativa, compasiva, religiosa y abnegada, estas características comienzan a mezclarse con la importancia de tener una figura acorde con los dictámenes estéticos impuestos por la publicidad de la época y así se establece durante toda la década el ideal de mujer, más bien opulenta, pero con "buenas formas", quien anhela: poseer curvas seductoramente femeninas, delicadamente redondeadas" (Publicidad de fajas Playtex, Cromos, Agosto 22, 1955, 3). Ellas quieren parecerse cada vez más a las divas del mundo del espectáculo; sin embargo, es importante aclarar que ese ideal se trasforma con el paso de los años. Al inicio, los modelos a imitar son actrices como Leslie Caron, Rita Hayworth y Lana Turner; mujeres ultra femeninas, con cuerpos en forma de reloj de arena, busto y caderas prominentes, cinturas diminutas, maquilladas y peinadas a la perfección. A medida que avanza la década, las mujeres intentan conservar la misma silueta, pero con un porte más desenfadado, menos circunspectas, mujeres que no se escandalizan al ver publicados anuncios de ropa interior femenina, señoras que se visten igualmente con pantalones pescadores y blusas ligeras que con faldas de enorme vuelo, como las propuestas por el gran diseñador de la época (Figura 8): Christian Dior, creador del New Look. Este tipo de mujer se ve encarnado en actrices, tales como Debbie Reynolds, Marilyn Monroe, Sofia Loren, o BrigitteBardot.

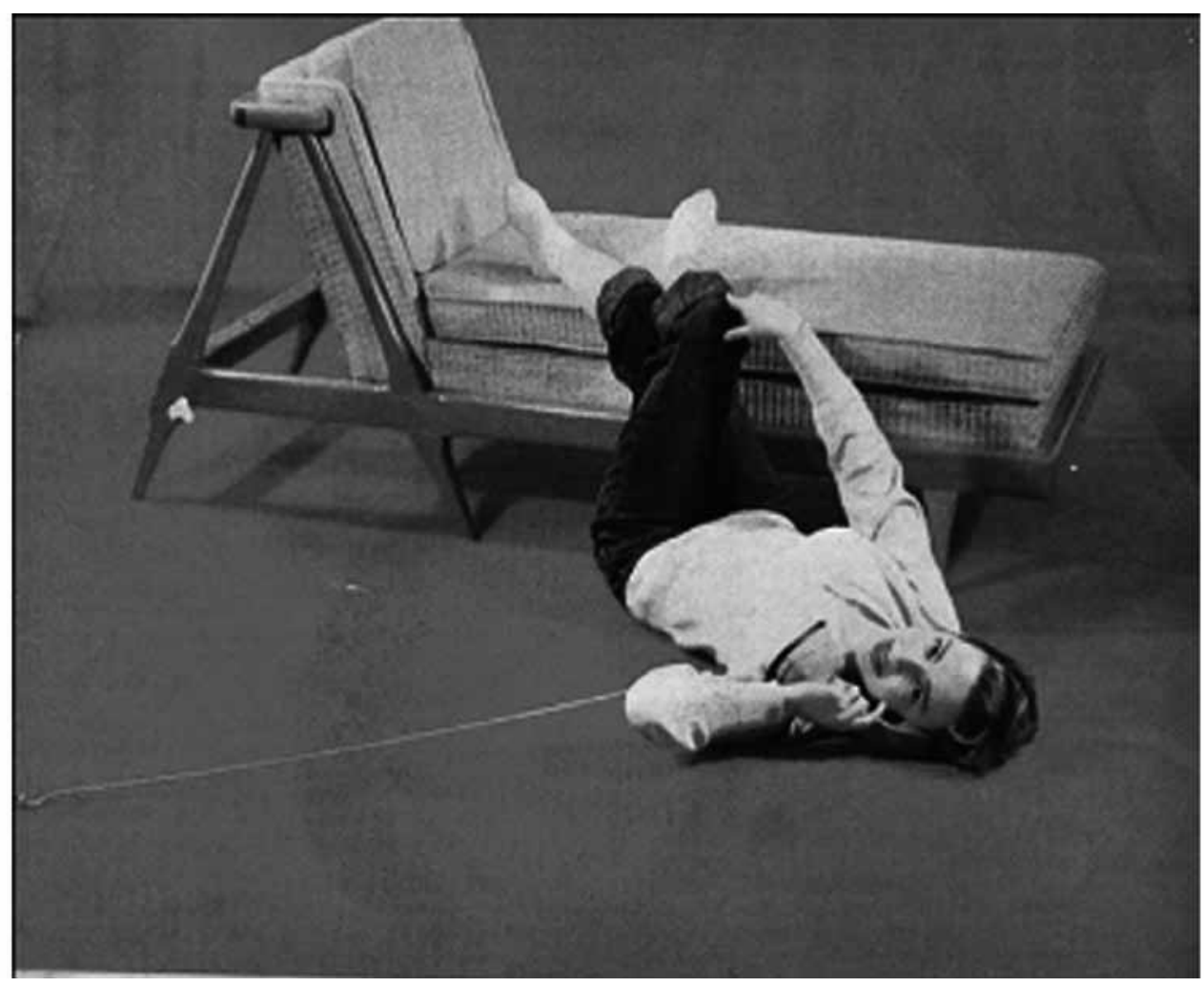

Figura 8: Esta publicidad connota un cambio enorme en la idea de mujer que parecería adelantarse a las amas de casa de su misma época. El uso de jeans y la pose descomplicada de la modelo, develan un cambio en la concepción del cuerpo que supone una idea de mujer, lista para moverse y conquistar otros espacios, además de esa esfera doméstica en que disfruta de una amena charla telefónica. (Revista Cromos, 1953) 
Por otra parte, Bogotá ya no es una ciudad aislada del resto del mundo. En 1954 la capital de la república se comunica de manera veloz a través de vuelos semanales en modernos aviones SuperConstellations con Europa, Israel y Estados Unidos. Avianca ofrece viajes todos los miércoles a Europa, con el eslogan de: viaje ahora y pague después con el nuevo plan de crédito de Avianca (Revista Cromos, Agosto 22, 1955, 10). De esta manera, se amplía la posibilidad para más mujeres bogotanas de conocer de primera mano los últimos dictámenes de la moda y adquirirlos, según la posibilidad económica, en las casas de alta costura europeas o en los innumerables almacenes de cadena estadounidenses que, para esa época, masificaban la moda con materiales menos finos, pero igualmente atractivos.

Otro hecho fundamental para la transformación del país, es el ocurrido el primero de diciembre de 1957, por primera vez se convoca a la población nacional a participar en un plebiscito en el que se consulta y se otorga el derecho al voto a las mujeres. No obstante, paradójicamente, todavía los columnistas de la revistas ven como una amenaza las transformaciones en el vestido y así como veinte años atrás se debate el uso del pantalón, en este momento le recomiendan a las jovencitas socializarse de la forma que lo hicieron sus madres, con el fin de tener una relación armónica con sus maridos.

Pierde mucho la que es poco femenina, artículo publicado en el año de 1953 que trata sobre la responsabilidad de la madre de guiar a las hijas hacia un comportamiento femenino en un momento en el cual, según la revista, se comenzaba a notar ciertos hábitos de niñas con conductas marimachas en su forma de vestir:

¿Puede una madre evitar que su hija adquiera cualquier hábito? Podría inculcarle el hábito de ir bien vestida (...) ¿cómo podrá una madre cooperar a que su hija se interese por las modas femeninas, o que le agrade presentarse bien vestida y como corresponde a una dama, -sin lastimar el deseo infantil de ir vestida exactamente como los demás elementos de su grupo-? La respuesta es muy sencilla y en realidad muy agradable: la madre debe llevar a las chiquillas de compras cada mes (Lamour, Revista Cromos Noviembre 11, 1955). 
En síntesis, aunque es un poco atrevido sacar conclusiones de una mirada tan panorámica, se puede decir que la capital de la república en la década del cincuenta del siglo XX da el salto definitivo hacía la modernización. No solo por lo anteriormente expuesto, sino por la inclusión de gran parte de sus habitantes de hábitos y costumbres más relajadas y alejadas de las estrictas formas coloniales o de los remedos de conducta victoriana que habían caracterizado a los bogotanos de élite hasta ese momento.

Cambios y permanencias que se van gestando desde los años 20 s en el vestido y en la ideas y que connotan abismos entre las formas traídas de fuera y las mentalidades de los capitalinos. Por ello visualizarlos requiere de un amplio período de estudio (19201960) en el que la investigación se detiene según temas más específicos que el panorama general que se quiso evidenciar en esta aproximación. Un acercamiento que da cuenta de las posibilidades de cruzar el material iconográfico con otro tipo de fuentes tradicionales y no tradicionales como entrevistas y literatura de la época, con el fin de reconstruir esas huellas de la vida privada de los capitalinos que expresan su idea de lo que son o lo que quieren llegar a ser mediante los vestidos que escogen. Maneras de estar, de sentirse y de habitar que implican mirar el diseño con relación a una cultura que ve materializarse sus miedos y aspiraciones en los objetos de los que se rodea cada grupo de individuos y sus formas de comunicarse con este rico lenguaje no verbal que constituye la indumentaria. 


\section{Notas}

${ }^{1}$ Maestra en Bellas Artes de la Universidad Jorge Tadeo Lozano de Bogotá.

Magíster en Historia y Teoría del Arte y la Arquitectura de la Universidad Nacionalde Colombia con mención meritoria. Profesora asociada de la Universidad de losAndes, Bogotá, Colombia. Cursos de especialización en Historia del Arte Medievaly Moderna realizados en la Universitádeglistudi di firenze, Italia, y de GrabadoArtístico en la Escuela de Artes y Oficios, la Llotja, Barcelona, España. En elcampo del diseño, se especializó en el diseño de modas con estudios de pregradoy maestría realizados en La Escuela de los Altos Estudios del Diseño, IDEP, de laciudad de Barcelona, España.

2. Profesional en Estudios Literarios de la Pontificia Universidad Javerianade Bogotá y magíster en Historia y Teoría del Arte y la Arquitectura de laUniversidad Nacional de Colombia. Candidata a doctora en Estética y Crítica,Arte y Arquitectura en la Universidad Nacional de Colombia. En su trayectoriacomo investigadora ha trabajado el tema de literatura y ciudad, en la tesis demaestría sobre El Carnero de Juan Rodríguez Freile — Bogotá 1538-1638 - . En la actualidad, con el grupo de

investigación Diseño y Cultura, adelanta lainvestigación: "Representaciones de modernidad a través del vestuario, Bogotá1920-1960".

\section{Referencias}

Álbum Familiar de Bogotá (2005), Bogotá, Instituto Distrital de Cultura y Turismo

Bourdieu, Pierre (1994): Distintion, A social critique of the judgement of taste, London: Routledge.

Castro-Gómez, Santiago, Tejidos Oníricos, Movilidad, capitalismo y biopolítica en Bogotá (1910-1930) (2009). Bogotá: Pontificia Universidad Javeriana.

Frisby, D. (1994): Modernidad y posmodernidad. George Simmel, primer sociólogo de la modernidad. México: Fondo de Cultura Económica.

Fundación Misión Colombia, Historia de Bogotá, Bogotá, Tomo I, siglo XX. Salvat Villegas, 1989.

Herrera R. y Carrizosa U. (1967): Sesenta y cinco años de fotografía (1865-1940): Bogotá, Carvajal.

Lehnert G. (2000): Historia de la moda del siglo XX, Colonia: Könemann Revista Cromos 1924 -1929, No. 388-692.

Uribe Celis, C. (1984). Los años veinte en Colombia, ideología y cultura. Bogotá: Ediciones Aurora.

Julier, G. (2010): La cultura del diseño, Barcelona: Gustavo Gili

Lleras Camargo, A.(1975): Mi gente, Bogotá: Banco de la República.

Recibido: 16 de octubre de 2012 Aprobado: 3 de diciembre de 2012 